Arq. Bras. Med. Vet. Zootec., v.69, n.3, p.597-599, 2017

\title{
Torção de cólon em um felino doméstico: relato de caso
}

\author{
Colon torsion in a domestic cat: case report \\ L.P. Souza, E.C. Bach, B. Lunardeli, C. Porto, T.R. Muller*, F. Salbego, \\ M.G. Luciani, D.S. Souza \\ Centro de Ciências Agroveterinárias - Universidade do Estado de Santa Catarina (CAV - Udesc) - SC
}

\section{RESUMO}

A torção de cólon em felinos é uma patologia rara. Os principais sinais apresentados são de abdome agudo e podem levar o animal rapidamente a óbito. O presente trabalho tem o objetivo de relatar um caso de torção de cólon em um felino. Este é o primeiro relato dessa enfermidade no Brasil. O diagnóstico foi realizado por meio do histórico e de exames de imagem. $\mathrm{O}$ animal foi encaminhado para a cirurgia, mas, devido à gravidade e extensão das lesões intestinais, foi realizada a eutanásia.

Palavras-chave: felino, cólon, torção, radiografia

\begin{abstract}
Colon torsion in felines is a rare pathology. The main signs presented are of acute abdomen and the condition can quickly lead to death. This paper aims to report a case of twisted colon in a feline. This is the first report of colon torsion in Brazil. The presumptive diagnosis was made through history and imaging. The patient was submitted to surgery, where, due to severity and extent of lesions, euthanasia was performed.
\end{abstract}

Keywords: acute abdomen, fecaloma, ischemia, necrosis

\section{INTRODUÇÃO}

A torção de alças intestinais é comumente relatada em animais de grande porte e em cães de raças gigantes. Em felinos, sua ocorrência é rara (Cairo et al., 1999). Na fisiopatologia da doença, o intestino se torce em torno de seu eixo, resultando em obstrução mecânica e estrangulante dos intestinos delgado ou grosso, compressão dos vasos locais, resultando em edema e ingurgitamento vascular da parede intestinal (Brown, 2003). O prognóstico é desfavorável devido à bacteremia resultante da translocação bacteriana através da mucosa intestinal isquêmica (Dow et al., 1989).

O diagnóstico presuntivo de torção de cólon pode ser realizado por meio das ferramentas de imagem. Quando a anamnese, os sinais clínicos e o diagnóstico por imagem sugerem fortemente uma obstrução intestinal, há a indicação

Recebido em 5 de agosto de 2016

Aceito em 10 de outubro de 2016

*Autor para correspondência (corresponding author)

E-mail: mullerusa@hotmail.com de uma laparotomia exploratória imediata (Walshaw, 1989). Enterectomia seguida de enteroanastomose é recomendada e pode ser bem-sucedida quando o diagnóstico é feito rapidamente (Knell et al., 2010).

O presente relato de caso tem o objetivo de descrever a ocorrência de uma rara enfermidade - a torção de cólon em um felino.

\section{RELATO DE CASO}

Um felino, fêmea, sem raça definida e de um ano de idade, foi atendido no Hospital de Clínica Veterinária do Centro de Ciências Agroveterinárias da Universidade Estadual de Santa Catarina com histórico, desde o nascimento, de paraplegia de membros pélvicos sem causa definida, com hábitos ativos e vivência em ambiente interno. Alimentava-se de ração seca associada a pastosa e apresentava quadros recorrentes de constipação. No momento 
do atendimento, o paciente apresentava fortes dores abdominais à palpação, distrição respiratória, prostração e três dias sem defecar. No exame físico, foram detectados desidratação de $8 \%$, aumento de volume abdominal à palpação, mucosas pálidas e taquicardia. Fluidoterapia e analgésicos foram administrados previamente ao exame radiográfico abdominal.

O exame radiográfico abdominal revelou, na incidência lateral, dilatação luminal de cólon ascendente, transverso e descendente por radiopacidade, gás e fezes formadas de radiopacidade mineral - compatível com fecaloma associado a megacólon. A incidência ventrodorsal de abdome identificou o cólon descendente cursando ao lado direito do abdome, diferente da sua posição habitual no lado esquerdo do abdome. Outra alteração identificada radiograficamente foi a perda de contraste radiográfico intra-abdominal, sugerindo efusão peritoneal que, consequentemente, indicou a possibilidade de ruptura de cólon e a presença de peritonite (Fig.1).

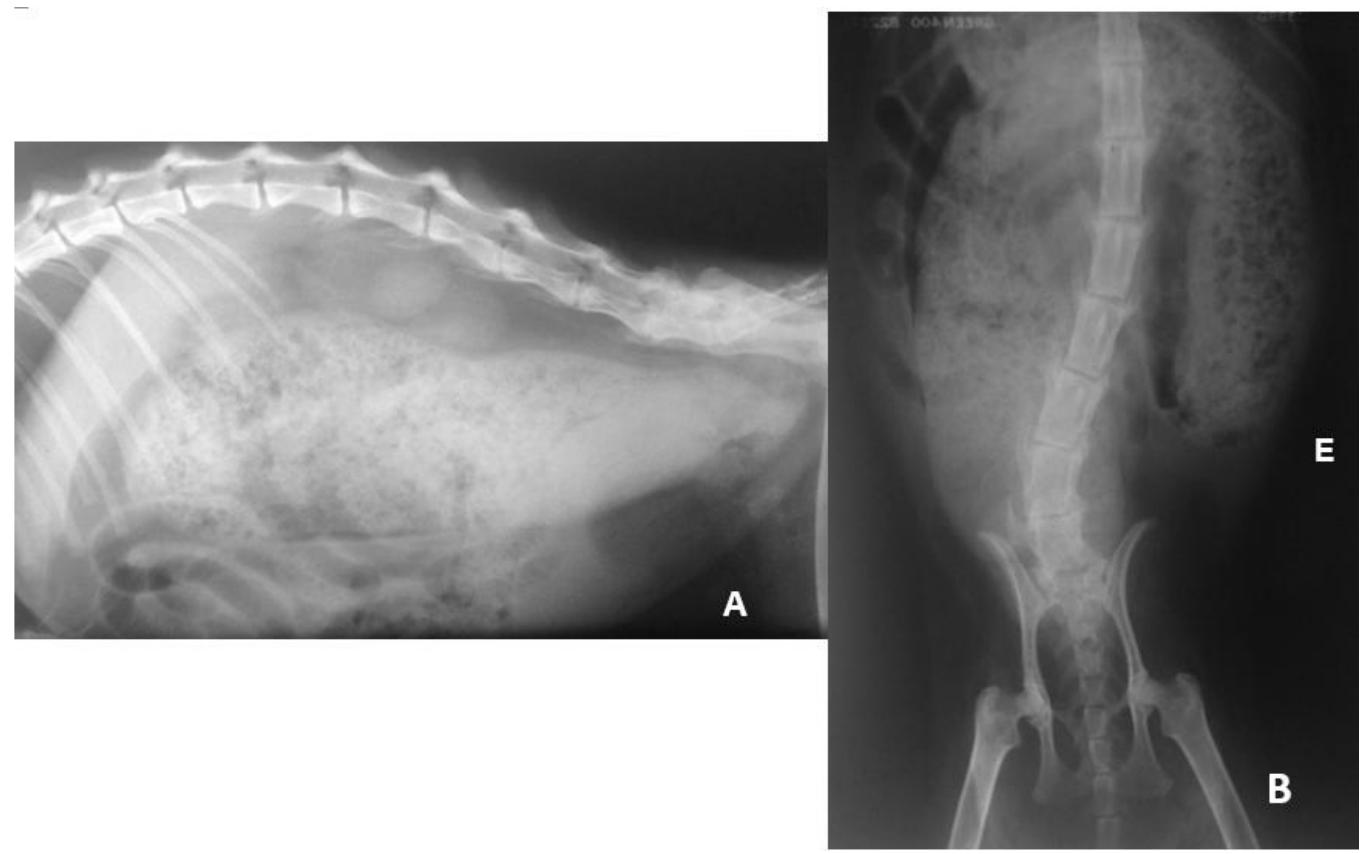

Figura 1. Exame radiográfico abdominal de um felino de um ano de idade apresentando torção de cólon com adicional quadro de fecaloma e megacólon. A: incidência lateral direita; B: incidência ventrodorsal; E: lado esquerdo.

Após o diagnóstico radiográfico de torção de cólon, o animal foi encaminhado para procedimento cirúrgico emergencial para correção e realização de colopexia. O paciente, entretanto, foi submetido a eutanásia durante a cirurgia, devido à gravidade e extensão de lesões isquêmicas e necróticas decorrentes da obstrução.

\section{DISCUSSÃO}

Os casos de torção gástrica ou de alças intestinais acabam levando a grande maioria dos pacientes acometidos a óbito, como relatado por Headlund et al. (2008). Por se tratar de uma emergência clínica e cirúrgica, é notório que o atendimento de urgência melhora o prognóstico, mas não há garantia de sobrevida, pois é ressaltado que a mortalidade se aproxima de $100 \%$ (Knell et al., 2010).

Os casos de torção mais comumente encontrados são os de mesentério e não o de cólon. Relatos prévios descrevem casos dessa enfermidade em felinos apresentando torção mesentérica, e relatos anteriores documentaram dois casos de pequeno vólvulo intestinal, ambos diagnosticados na necropsia, e mais um caso de torção de cólon em um paciente felino que morreu após a cirurgia (Knell et al., 2010). 
O exame radiográfico é o mais indicado para identificar as causas subjacentes para constipação, obstipação e megacólon em gatos, além de observar o conteúdo e o diâmetro do cólon (Bertoy, 2002). Assim, o diagnóstico de torção de cólon e de megacólon baseia-se numa combinação do histórico de constipação crônica que não é sensível ao tratamento clínico, à palpação abdominal de um cólon distendido e à detecção radiográfica de um cólon dilatado por conteúdo fecal impactado (Bertoy, 2002).

Quando o diagnóstico é realizado de forma rápida, o procedimento cirúrgico é indicado emergencialmente (Knell et al., 2010). O prognóstico é reservado a desfavorável mesmo em casos em que a realização de enterectomia seguida de enteroanastomose é bem-sucedida devido às alterações hemodinâmicas decorrentes da hipóxia tecidual intestinal. No presente caso, a área de necrose acometida era muito extensa, estendendo-se do reto até o duodeno, o que impossibilitou a realização do procedimento cirúrgico, optando-se, portanto, pela eutanásia do paciente.

\section{CONCLUSÕES}

A torção de cólon em felinos é algo extremamente raro, sendo o presente relato o segundo caso encontrado na literatura consultada. Mesmo com um diagnóstico rápido por meio da anamnese e de radiografias, o prognóstico do animal ainda é desfavorável, como observado no caso descrito. Pacientes com obstruções colônicas crônicas, megacólon e com quadros de fecaloma podem apresentar predisposição para essa enfermidade. Não se deve abrir mão do procedimento cirúrgico, pois além de confirmar o diagnóstico, no primeiro relato dessa enfermidade (Knell et al., 2010), o paciente sobreviveu ao tratamento. Este é o primeiro relato dessa enfermidade no Brasil, e é importante sua divulgação para a comunidade científica.

\section{REFERÊNCIAS}

BROWN, D.C. Intestino delgado. In: SLATTER. D. Manual de cirurgia veterinária. 3.ed. St. Louis: Elsevier, 2003. cap.41, p.660-661.

CAIRO, J.; FONT, J.; GORRAIZ, J. et al. Intestinal volvulus in dogs: a study of four clinical cases. J. Small Anim. Pract., v.40, p.136140, 1999.

DOW, S.W.; CURTIS C.R.; JONES R.L.; WINGFIELD W.E. Bacterial culture of blood from critically ill dogs and cats: 100 cases (19851987). J. Am. Vet. Med. Assoc., v.195, p.113$117,1989$.

KNELL, S.C.; ANDREONI A.A.; DENNLER M.; VENZIN C.M. Successful treatment of small intestinal volvulus in two cats. J. Feline Med. Surg., v.12, p.874-877, 2010.

HEADLUND, C.S.; JOHNSON A.L.; SCHULZ $\mathrm{K} . \mathrm{S}$; et al. Cirurgia do sistema digestóriovôlvulo e torção intestinais. In: FOSSUM, T.W. et al. Cirurgia de pequenos animais. [Texas]: Elsevier, 2008. cap. 19, p.477-480.

WALSHAW, R. What is your diagnosis? J. Am. Vet. Med. Assoc., v.194, p.1631-1632, 1989. 